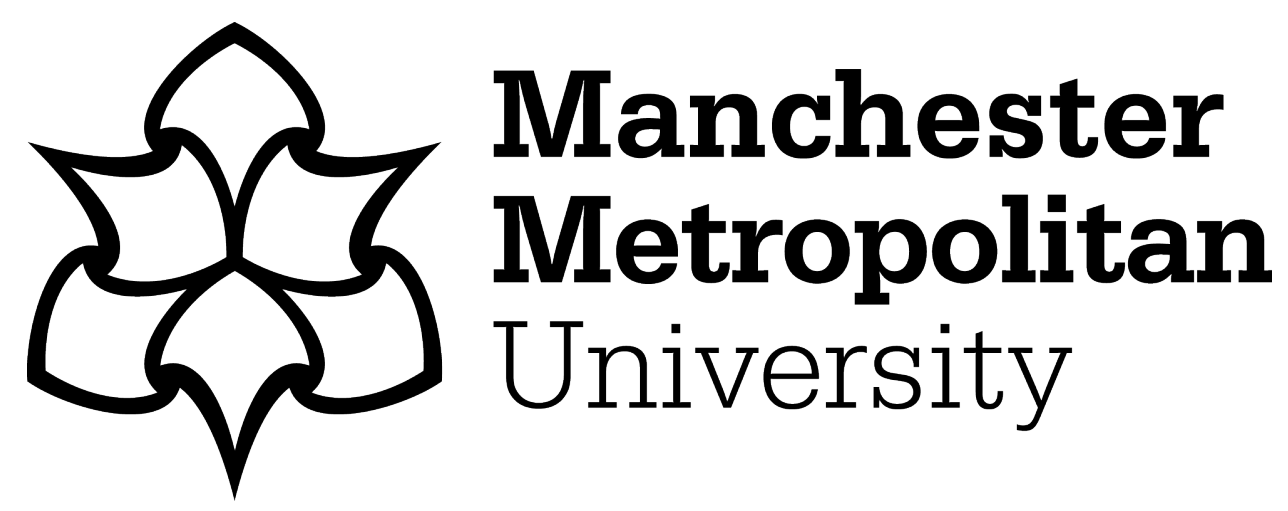

Berg, Brennan K, Inoue, Yuhei ORCID logoORCID: https://orcid.org/00000002-1983-6217, Bowers, Matthew T and Chelladurai, Packianathan (2022) "Sport is Double-Edged": A Delphi Study of Spectator Sport and Population Health. Journal of Sport Management, 36 (4). pp. 341-354. ISSN 0888-4773

Downloaded from: https://e-space.mmu.ac.uk/628776/

Version: Accepted Version

Publisher: Human Kinetics

DOI: https://doi.org/10.1123/jsm.2020-0399

Please cite the published version 
"Sport is double-edged": A Delphi Study of Spectator Sport and Population Health

\author{
Brennan K. Berga \\ The University of Memphis \\ Yuhei Inoue ${ }^{b}$ \\ Manchester Metropolitan University \\ Matthew T. Bowers ${ }^{\mathrm{c}}$ \\ University of Texas at Austin \\ Packianathan Chelladurai $^{\mathrm{d}}$ \\ Troy University
}

${ }^{a}$ Sport and Leisure Management Program, Kemmons Wilson School of Hospitality and Resort

Management, The University of Memphis, Fogelman Executive Center 236, Memphis, TN 38152, United

States, Email: bberg@memphis.edu

${ }^{\mathrm{b}}$ Sport Policy Unit, Department of Economics, Policy and International Business, Manchester

Metropolitan University, Room 4.09 Business School, Oxford Road, Manchester M15 6BH, United

Kingdom, Email: y.inoue@mmu.ac.uk

${ }^{\mathrm{c}}$ Sport Management Program, Department of Kinesiology and Health Education, University of Texas at Austin, 2109 San Jacinto Blvd. D3700, Austin, TX 78712, United States, Email:

mattbowers@austin.utexas.edu

d Sport Management Program, School of Hospitality, Sport, and Tourism Management, Troy University, 288 Grangeover Avenue, London, Ontario, Canada, N6G 4K5, Email: chella@troy.edu

Corresponding author: Brennan K. Berg. Tel.: +1 901678 2462; Fax: +1 9016780034. 


\begin{abstract}
The periodic examination of research agendas in sport management is necessary for the field's advancement. In this mixed-method Delphi study, 15 leading sport management scholars forecast how the field can have a more influential voice in understanding the relationship between spectator sport and population health. Panelists agreed on the importance to not oversell or oversimplify the role of spectator sport; to improve interdisciplinary collaboration, theorization, and research design; to recognize opportunities to advance mental and social well-being; to better relate to stakeholders; and to identify distinctive health effects of spectator sport. A lack of consensus existed about the relationship between spectator sport and environmental well-being and prospects for leveraging spectator sport for participant sport. Drawing from these findings, we suggest that future research considers moving beyond simply measuring the effects of spectator sport on population health and instead assess its health effects relative to multiple forms of leisure and entertainment.
\end{abstract}

Keywords: spectatorship, sport events, mental well-being, social well-being, participant sport, environmental well-being 


\section{"Sport is double-edged": A Delphi Study of Spectator Sport and Population Health}

As the sport management field continues to evolve, the salience and trajectory of various research topics will also evolve based on previous empirical study and the current sport context. The ability for the field to evolve is recognized as necessary for sport management's continued advancement, relevance, and prospects for interdisciplinary collaboration (Chalip, 2006; Chalip et al., 2010; Costa, 2005; Doherty, 2012). For instance, the role sport may have in promoting the health of the population, or population health, has been widely examined by sport management scholars (Berg et al., 2015; Chalip, 2006; Edwards \& Rowe, 2019; Inoue et al., 2019; Inoue, Berg et al., 2015; Rowe et al., 2013). One significant subtopic within the sport and population health discourse is understanding the relationship between spectator sport-sport and athletic events provided as entertainment for consumers (Chelladurai, 2014)_and population health. While the commercialization and economic opportunities of spectator sport have received considerable attention in sport management (Chalip et al., 2010), the role of spectator sport in advancing population health has been less developed and promoted (Inoue, Berg, et al., 2015).

As one might expect, active participation in sport has been more frequently linked with population health to understand how it can benefit physical, mental, and social well-being (e.g., Berg et al., 2015; Rowe et al., 2013). However, sport spectatorship has also been shown to have the capacity to contribute to public policy goals by promoting multiple aspects of well-being, such as an improved sense of belonging or a higher quality and quantity of social relationships. Within and outside the sport management field, scholars have increasingly examined how spectator sport may influence various dimensions of population health (e.g., Inoue, Berg, et al., 2015; Inoue et al., 2017, 2019; Taks et al., 2016). In order for the field to accurately inform public policy discourse, the non-economic value of spectator sport must be established to benefit 
population health decisions, such as resource allocations or promotional messages for leisuretime use. Sport management scholars currently lack consensus on what specific research issues may need to be addressed to advance the field's understanding of the relationship between spectator sport and population health. As Mahony (2008) noted in his acceptance of the North American Society for Sport Management (NASSM) Zeigler Award, "many individuals have developed research agendas for themselves, but research agendas for the field are rarely discussed" (pp. 4-5). Facilitating conversations among scholars has the potential to generate a spectator sport research agenda that may help reduce inadequately managed sport organizations and events, which in turn could enhance any positive influence spectator sport can have on population health and alleviate its detrimental health effects (Chalip, 2006; Inoue et al., 2020; Kelly et al., 2014; Wakefield \& Wann, 2006).

Empirically derived paradigms are needed for the spectator sport and population health agenda to advance. A paradigm refers to "a constellation of concepts, values, perceptions, and practices shared by a community, which forms a particular vision of reality that is the basis of the way the community organizes itself' (Capra, 1996, p. 6). Paradigms in sport management are not permanent and will adjust as members of the field use new lenses to view the world and identify prevailing assumptions and values. As other scholars have noted (Amis \& Silk, 2005; Collis \& Hussey, 2014; Costa, 2005; Frisby, 2005), new paradigms, which do not always function in opposition to other paradigms, will emerge and offer alternative direction to the ontological (i.e., nature of reality), epistemological (i.e., how the world and topics are viewed), and methodological (i.e., how knowledge is to be acquired) positions taken toward a research area.

As it is infeasible for the advancement of knowledge to be directed by one individual, paradigmatic modification necessitates cooperative input (Costa, 2005). Kuhn (1996) noted that 
it is acceptable to have competing outlooks and theories to allow for more rigorous discourse between different segments of a discipline, which may allow for eventual consensus. Thus, paradigmatic advancement in sport management inherently compels input from leading experts who have diverse research backgrounds representing an array of sport contexts. Otherwise, sport management is susceptible to an uncoordinated research agenda lacking purpose due to unclear paradigms guiding it. Frisby (2005) explained that the paradigms researchers operate from will shape the questions asked, the methods used, and the impact of empirical findings on society. The emerging paradigms regarding the role of spectator sport on population health, drawn from consensus among leading sport management scholars, may influence the approaches and standards of empirical study necessary for knowledge expansion to occur in the field.

The purpose of this study is to understand the present state of, and future needs for, spectator sport and population health research by identifying the prevailing paradigms in the sport management field on this topic. In doing so, it contributes to the literature by (a) generating a sport management research agenda for the broad and encompassing spectator sport and population health topic, (b) allowing for critical assessment of research synthesis and practitioner consultations through the viewpoints of sport management scholars who have a range of research interests and expertise, and (c) offering insights from experts in the field that may inform sport management research in general.

\section{Spectator Sport and Population Health Research}

The World Health Organization (n.d., para. 1) defines health as "a state of complete physical, mental and social well-being and not merely the absence of disease or infirmity." Based on this broad definition of health, population health — as a concept — is concerned with physical, mental, and social well-being outcomes of a population unit, including groups of individuals 
within a certain geographic boundary (e.g., local residents) or those who share a common attribute (e.g., college students supporting their university's sport teams) (Kindig, 2007). As a research field, the goal of population health scholarship is to understand how systematic and environmental variables, such as governmental policies and interventions, sociodemographic characteristics, and quality of health care systems, may make certain populations healthier than others (Kindig, 2007).

Increasingly, spectator sport has been examined as one of the variables that may influence the health of a population (e.g., Lera-López et al., 2020; Pawlowski et al., 2014; Taks et al., 2016). Inoue, Berg, et al.'s (2015) scoping study classified studies examining the relationship between spectator sport and population health into nine research themes (see Table 2 of Inoue, Berg, et al., 2015, for descriptions of each theme). These themes illustrated how services offered by spectator sport entities — spectator (e.g., events), sponsorship (e.g., in-game advertisements), and social idea (e.g., community outreach programs) services - may influence either of the three domains (physical, mental, social) of well-being identified in the World Health Organization's (n.d.) definition of health. Some of the themes are also concerned with the effect of spectator sport on health-related behaviors (e.g., physical activity, food and beverage consumption), which would in turn have a more immediate influence on each well-being domain (Inoue, Berg, et al., 2015).

Since the publication of Inoue, Berg, et al. (2015), several studies have been published in both sport management (e.g., Collins \& Heere, 2018; Schlegel et al., 2017; Taks et al., 2016) and non-sport management journals (e.g., Inoue et al., 2018; Lera-López et al., 2020; Wann et al., 2017) to explore the relationship between spectator sport and population health. In relation to the physical well-being domain of population health, an analysis of multi-year secondary data in 
Japan found that attendance at sport events was positively associated with individuals' subjective perceptions of physical well-being as measured by a self-rated health scale (Inoue et al., 2018). In Lera-López et al.’s (2020) study of 1,632 Spanish adults, study participants with greater levels of spectator sport involvement (as measured by such variables as the frequency of sport event attendance, watching sport games on television, and reading sport news) tended to report higher ratings of mental well-being (as measured by happiness). The positive relationship between spectator sport and mental well-being was further supported by Schlegel et al.'s (2017) investigation of the impact of hosting the 2014 FIFA World Cup on residents in Rio de Janeiro. By analyzing data collected before and during the mega-event, the researchers found that residents experienced greater levels of subjective well-being during the event, compared to before the event (Schlegel et al., 2017).

Similarly, researchers examining spectator sport's connections with social well-being provided evidence that individuals' engagement in spectator sport may contribute to this population health domain (e.g., Collins \& Heere, 2018; Inoue, Funk, et al., 2015; Wann et al., 2017). For example, both Inoue, Funk, et al. (2015) and Wann et al. (2017) demonstrated that identification with local sport teams had a positive association with social well-being measures, such as sense of belonging and community cohesion. Through an ethnographic study of a fan group supporting a non-local professional sport team, Collins and Heere (2018) provided rich qualitative data illustrating how fans' involvement with the group, and resultant sense of social identity as a group member, helped them develop social capital. These data imply the role of spectator sport in promoting social well-being, as social capital and social well-being are closely linked to each other (Soria \& Stebleton, 2013).

While the studies reviewed above seem to indicate the benefits of spectator sport for 
population health, there is a body of evidence suggesting that spectator sport may have nonsignificant — or even negative_ effects on population health (Inoue, Berg, et al., 2015). For example, Pawlowski et al.'s (2014) analysis of survey data from residents of 33 countries found that feelings of pride residents experienced from their countries' success at international sport competitions did not influence their subjective well-being. By comparing the number of cardiovascular events in the greater Munich area during the months when the 2006 FIFA World Cup were held in Germany and during the same months in 2003 and 2005, Wilbert-Lampen et al. (2008) concluded that watching the host country's matches more than doubled the incidence of cardiovascular events. Because of this mixed evidence, some researchers highlighted the needs for examining underlying psychological mechanisms (Wann et al., 2017) and longitudinal effects (Kim \& James, 2019) to advance spectator sport and population health research.

In sum, the diversity of topics examined in previous research suggests that investigations into the relationship between spectator sport and population health present sport management scholars with numerous research opportunities. At the same time, this broad scope may create obstacles when scholars seek to produce a body of knowledge distinctive to the sport management discipline (Chalip, 2006; Chelladurai, 1992). Such an endeavor requires creating a shared understanding of research priorities that facilitate active communications and cooperation and enable coordinated efforts to develop in-depth and focused knowledge (Chelladurai, 1992).

Because sport management is an applied academic field, conducting research that both informs and is informed by the interests of practitioners is essential (Irwin \& Ryan, 2013; Weese, 1995). Hence, one way to determine common research priorities is to understand and reflect practitioner insights on key issues and challenges in establishing the link between spectator sport and population health. Inoue et al. (2019) sought to achieve this by undertaking a consultation 
exercise with 136 employees of U.S. intercollegiate athletic departments. By analyzing quantitative and qualitative data obtained from these employees through an online survey, the researchers reported two main findings. First, of the nine research themes identified by Inoue, Berg, et al. (2015), the three themes rated as most important by employees were "social psychological benefits of sport spectatorship," "psychological impact of sport spectatorship," and “event's impact on sport and physical activity participation" (p. 712). Coincidently, these three themes were the most frequently examined themes based on Inoue et al.'s (2019) follow-up review of articles that were published in premier sport management journals from 2014 to 2018 , pointing to convergence between the interests of sport management practitioners and those of researchers. However, the results also revealed some divergence: the theme of "event's impact on physical impairment and mortality," which was the most researched theme according to Inoue, Berg, et al.'s (2015, p. 712) scoping review, was deemed least important by college athletics employees (Inoue et al., 2019). Second, employees' qualitative responses indicated that they defined the concept of population health more broadly than the conventional definition above (Inoue et al., 2019). In particular, some employees highlighted that eudaimonic well-being (i.e., personal growth and human development; Ryan \& Deci, 2001) and environmental wellbeing (i.e., protection of the natural environment; Musa et al., 2015) constitute important facets of population health as they relate to spectator sport.

Overall, Inoue et al.’s (2019) findings, as informed by practitioners' opinions, offer initial insights into the development of shared understanding within the sport management discipline, with respect to central research priorities and issues concerning the link between spectator sport and population health. However, beyond gaining practitioner insights, it is important to examine the viewpoints of leading sport management scholars who can consider specific definitional, 
theoretical, and methodological issues in advancing this line of research. We thus turn to the discussion of the Delphi technique to review its strengths for building consensus among experts.

\section{The Delphi Technique as a Tool for Paradigmatic Advancement}

The Delphi technique is an iterative, group-facilitation method used to transform expert opinions and feedback to group consensus (Jacobs et al., 2014). Originally developed by the RAND Corporation during the 1950s for a U.S. Air Force commissioned project, it integrates various characteristics to ensure that researchers "obtain the most reliable consensus of opinion of a group of experts" (Dalkey \& Helmer, 1963, p. 458). These characteristics are iteration, anonymity, controlled feedback, and use of statistics for aggregating group responses (Rowe \& Wright, 1999). First, the Delphi technique involves the iteration of data collection over multiple rounds, which affords participants with the opportunity to update or change their judgements and opinions based on the responses provided by other participants. Second, with the use of anonymous questionnaires, this technique allows for providing opinions privately and lessening pressures to follow dogmatic or dominant individuals or fear of losing face due to changes to judgements in a later stage. Third, the research team delivers controlled feedback to participants to expose them to a variety of opinions and responses provided by other anonymous participants throughout different stages. Finally, at the end of a Delphi study, participants' responses are summarized using the statistical average (mean or median) so that the final judgement reflects an equal weighting of responses from all members of an expert panel (Hsu \& Sandford, 2007; Rowe \& Wright, 1999). Given the likelihood that a diverse group of experts will not have complete agreement on every issue queried, the Delphi approach permits points of consensus and nonconsensus to be accurately distinguished for a topic. The points of consensus represent paradigms to guide future research while points of non-consensus signify issues to be debated 
and individually explored by scholars.

According to Pfleegor et al. (2017), a Delphi study can be a uniquely useful methodological lens when the research topic is complex and has been inadequately articulated within the extant literature, as is the case with understanding the relationship between spectator sport and population health. In that sense, the advantages of the Delphi technique to build consensus among a group of experts would outweigh its potential shortcomings (Hsu \& Sandford, 2007), particularly given that it has been established as a viable research approach in the sport management field. Scholars such as Costa (2005) and Bowers et al. (2014) used this method to examine future opportunities and challenges facing sport management as an academic field. Other Delphi studies examined more specific issues, such as the optimal designing and delivery of sport-for-health programs for refugee populations (Anderson et al., 2019) and environmental sustainability in the management of sport facilities (Mallen et al., 2010). This latter type of work addressing specific issues collectively demonstrates that the Delphi technique is useful when researchers attempt to gain expert perspectives on a topic that is considered (relatively) new to the sport management field.

In this study, we employed the Delphi technique to facilitate discussions among leading sport management scholars regarding the present state and future needs for spectator sport and population health research, as well as its place in the sport management field. Similar to the approach used by Bowers et al. (2014), the empirical orientation of this Delphi study enabled the expert panel to direct the reflections and projected path of spectator sport and population health research. Therefore, prior to the empirical investigation, we did not assume an a priori theoretical framework from the outset (e.g., Pfleegor et al., 2017) given the expansive and complex topic under consideration. In sum, using the Delphi technique, the current study addressed the 
following research questions to identify prevailing paradigms:

RQ1: What is the present state of spectator sport and population health research?

RQ2: What are the future needs to advance spectator sport and population health research?

\section{Method}

\section{Participants}

We used the Delphi technique as a mechanism for aggregating and synthesizing the perspectives offered by an expert panel of sport management scholars. Like any instance of utilization of the Delphi technique, we traded breadth and representativeness in participant sampling for a narrow, highly targeted group of experts who can help co-create and co-define the key areas for investigation. As a result, this study specifically targeted sport management scholars whose research was linked to or directly addressed spectator sport and population health as potential participants. This included NASSM Research Fellows and other sport management scholars who have published research on at least one aspect of spectator sport and population health. Based upon the inclusion criteria we established, an initial pool of 53 scholars, working in six countries on four continents, was identified and sent invitation emails to gauge interest in participating in the study. Of the 53, 20 participants responded to one of two email solicitations with their agreement to serve on the expert panel. Panelists participated voluntarily without any incentive offered. The 20 panel members worked for 19 universities, held various research interests, and were based in four countries (i.e., USA, UK, Canada, Australia).

The Delphi technique is a flexible research method that allows for adaptable designs based on a study's context (Skulmoski et al., 2007). Largely due to varying ranges of expertise for different topic areas, sample sizes for Delphi studies are not uniform across disciplines. 
However, the initial (and final) sample size for the present study falls within the realm of typical sample sizes across the body of literature utilizing the approach. With 15 to 20 participants asserted by scholars as the adequate or optimal range for a Delphi panel (Anderson et al., 2019; Costa, 2005; Dalkey et al., 1970), we concluded participant recruitment once the higher end of this range was reached (Skulmoski et al., 2007). As Bowers et al. (2014) pointed out, Delphibased studies have been published with as few as three expert participants and it is more imperative to view the degree of appropriateness of sample size through the lens of quality over quantity (cf. Skulmoski et al., 2007). This emphasis on quality over quantity ties directly to more salient factors than sample size, such as accounting for a diversity of perspectives and experiences and the extent to which additional participants add unique value to the sample.

\section{Data Collection and Analysis}

Having established a dynamic (and defensible) sample of expert panelists, we undertook the process of developing the framework for the three rounds of data collection in accordance with established protocols within the literature. Modeling the procedures adopted by Costa (2005), Bowers et al. (2014), and Pfleegor et al. (2017), the three rounds of data collection and synthesis followed the basic pattern of participants responding to open-ended questions, using those responses to generate opportunity for deeper reflection and interpretation, and having participants assess their levels of consensus both quantitatively and qualitatively.

In Round 1, a questionnaire (see Appendix A) consisting of five open-ended questions was emailed to the 20 participants who agreed to participate. Seventeen of the 20 participants responded within the three weeks given for completion. This timeframe for completion was uniform across all three rounds and allowed for accommodation of panelists' schedules. The 17 respondents in Round 1 were given code names (Panelist 1, Panelist 2, etc.) for when results 
were later reported. After the return of the 17 questionnaires, we adhered to the data analysis protocols utilized within the sport management-specific Delphi studies. These protocols employ a relatively straightforward content analysis first established in a sport-specific Delphi study by Costa (2005), but which derived from Weber (1990). Using QSR International's NVIVO 12 software, the first and second authors independently analyzed the qualitative data to generate as many codes and concepts as possible. This opening coding process produced 52 first-level codes in which the ideas or opinions of the expert panel were classified by type and assigned one or multiple code names (Patten, 2014). NVIVO enables the strength or frequency of phenomena in the data to be quantified and more accurately categorized through first-level coding (Berg et al., 2018). Upon completion of independent coding, the first and second authors then grouped the codes to begin establishing significant themes guided by Capra's (1996) paradigm definition. The third author evaluated the codes ascribed by the first two authors and corroborated that all codes and themes represented the meaning of respondents' statements. Such peer review enhances trustworthiness by having multiple researchers look at preliminary results and submit ideas or opinions that may have been missed. This approach also decreases researcher subjectivity or bias while producing a complete and consistent analysis (Goulding, 2002). Drawing upon significant themes identified in the Round 1 data, we derived the Round 2 prompts and questions (see Appendix A) from a synthesis of the first-round responses.

In Round 2, the synthesized questionnaire was sent to the 17 respondents from Round 1, with 16 respondents returning the questionnaire for this round. In alignment with the approach of Pfleegor et al. (2017), Round 2 asked participants to reflect on and respond to "a combination of the compiled expert comments from Round [1], investigator introductory comments vis-à-vis common categories from the responses, and questions devised from the items of consensus and 
non-consensus" (p. 194). This approach invites panelists to engage with the data at multiple levels, from directly commenting on specific quotes or ideas to offering more general commentary on the trends emerging from the responses. Upon completion of data collection in Round 2, we used the same approach employed in Round 1 to analyze the panel's statements, which produced 64 first-level codes, and ascertain significant themes, which generated the statements presented to the participants in Round 3 (see Appendix B).

Round 3 entailed a methodological shift toward a quantitative, Likert-type response scale. Of the 16 remaining panelists from Round 2, 15 returned the Round 3 survey. Both Bowers et al. (2014) and Hsu and Sandford (2007) advocated for a shift to a Round 3 quantitative scale. The scale is designed to assess levels of agreement or disagreement with the points of consensus emerging from Rounds 1 and 2, which allowed panelists to make clear their perspectives on the emerging discourse. Rather than a more sweeping qualitative overview of the responses, we ensured that each individual panelists' voice was considered when assessing whether the points of consensus emerging from the panel's qualitative responses were reflective of their individual perspective. This was done to account for the potential for panelists to feel compelled toward consensus if, in fact, they were disinclined to agree with the panel.

\section{Results}

With quotations that best exemplified and summarized the panelists' perspectives provided, we present each of the primary themes through the emergent paradigms emphasized or debated by the panelists across all three rounds.

\section{Overselling or Oversimplifying Sport: Stand Clear}

The first theme was rated the most important issue by the panel in the Round 3 survey. Members of the panel stressed the significance of spectator sport not being oversimplified or 
oversold in the benefits it can offer any aspect of population health. With broad questions being asked in the first round of data collection, the panelists began narrowing in on this note of caution that was evident by the end of Round 3. For instance, Panelist 7 stated the following in Round 1 on potential health benefits through spectator sport:

...This connection is mediated by a number of variables. Being a spectator makes you feel better during the game (situational benefits) and if the team wins there could be some lingering winning benefits by talking with friends and enjoying the winning moment.

This would lead to happiness for that event. But to connect to overall quality of life, it is a big jump. So, it is not a direct relationship and needs to be explored more.

By the completion of Round 2, this theme emerged after being repeatedly emphasized by members of the panel. Panelist 1 represented the panel by writing "I believe it is important to look to sports as a piece of the puzzle and don't try to oversell its importance." Other panel members underscored the importance of not overselling the benefits of spectator sport and overlooking the detrimental outcomes to population health. Panelist 2 wrote "The point is that we need to be careful about a positive bias in our work. We need to examine potential negatives as well as potential positives. Sport is double-edged [emphasis added]." Panelist 11 explained: There can be no assumption that the relationship between spectator sport and population health is necessarily a positive one... The problem with examining the role of spectator sport in creating behavior change among the population is that sport spectating does not occur in a vacuum. With the passage of time, people are exposed to different things and experience many life events, which have a contaminating effect and make it difficult to attribute causality for any behavior changes to spectator sport.

Overall, the panelists advocated for an altered premise of spectator sport. 
Round 3 provided confirmation of the importance placed on this theme by the panel. As shown in Appendix B, the statement "Sport management researchers must avoid overselling or oversimplifying the role spectator sport can have to benefit population health" had the highest mean rating $(M=6.67)$ and lowest standard deviation $(S D=.49)$ among the 11 statements scored in the final round. Thus, there was not only a high level of importance, but also consensus placed on this issue by the expert panel.

\section{Improving Interdisciplinary Collaboration, Theory, and Research Design}

From the outset of data collection, panel members discussed the necessities for improving empirical study of the link between spectator sport and population health. This included the importance of bridging with other disciplines, better theorization, and refining the design of research. Responses in Round 1 focused on upgrading the empirical propensities in which spectator sport research is conducted. For example, Panelist 9 articulated:

We know little about how success and failure affect well-being (for example) over time. By this, I mean in the days and weeks after success or failure. Temporality as it relates to any benefit of sport seems an important domain to pursue because at present much work is correlational and cross-section, which is prone to observing chance events.

Panel members concurred with the temporality consideration. Many promoted more longitudinal research to better understand the long-term feasibility of spectator sport influencing any aspect of population health as well as underlying processes that explain such influence. Panelist 15 explained "We have a pretty good understanding of [correlations] (not complete, but pretty good). What is missing is the process. Additionally, we are in desperate need for longitudinal and cross-cultural work in this area." In Round 2, these emphases persisted. Panelist 1 articulated why interdisciplinary collaboration was critical: 
...One of the challenges is to start working with academics/practitioners from other disciplines such as sport sciences, medicine, and nutrition. I believe that collaborative work may be the key because we all have different skills that, if used in a collaborative way, can help leverage sport as a tool to promote population health. The challenge is to recognize that we all need each other.

Thus, there was consensus among the panel that researchers cannot treat sport management scholarship in isolation from other fields. Additionally, panelists urged better theoretical frameworks as part of the collaboration with other disciplines. Panelist 2 conveyed why sound utilization and contribution to theory were crucial:

Theorization is key. Too much of our work has been uninformed by theories of alienation, anomie, ethnic/cultural difference/contact, and the social psychology of community. We need to mine those theories and use them to accelerate and deepen our work in this realm... It is time to get beyond seat-of-the-pants speculation.

In agreement, Panelist 15 stated "There are many theories within psych[ology] that help us understand what's happening within fans with respect to fandom and their well-being. But very few sport marketers are aware of this work." By the end of Round 2, it was evident that these calls to the sport management field would be significant in the final data analysis.

In the Round 3 survey, a high level of importance was placed on two statements for this theme (see Appendix B). The statement "Collaboration with other disciplines beyond sport management will be important in advancing the topic of spectator sport and population health" $(M=6.53, S D=.83)$ received the second highest mean score. Further, the statement "Improvements in research designs and theorization are crucial to offer robust evidence regarding the relationships between spectator sport and population health" $(M=6.07, S D=.59)$ 
was assigned the fourth highest mean score by the panel.

\section{Opportunities with Mental and Social Well-Being}

Presented with multiple domains of population health, the panel frequently returned the discourse to the aspects of health beyond any physical effect. Specifically, the panelists noted the importance and potential of spectator sport to influence mental and social well-being. These well-being components were discussed from the outset of data collection due to the panel viewing the physical outcomes of sport spectating as unsubstantiated and/or antithetical to health, such as consumers' lack of physical activity or poor nutrition choices while watching others play sport. For instance, in Round 1 Panelist 4 explained the relevance of mental wellbeing through spectator sport by stating "The impacts on mental health - through well-being and diet are important. This is because viewing is passive, so the physical health benefits are tenuous." A similar discussion proceeded into Round 2. Panelist 11 explained:

... Researchers investigating the relationship between spectator sport and population health should consider broadening the definition of 'health' to include indicators of mental well-being (e.g., life satisfaction, happiness, anxiety, etc.) and social well-being (e.g., pride, sense of belonging, social trust, etc.).

Panelist 15 noted "But the link between fandom and mental health, that's got great possibilities... The question is how." The panel rated the statement "Enhancing mental well-being (e.g., life satisfaction, happiness) is an important and viable opportunity for spectator sport to benefit population health" with the third highest mean score $(M=6.13, S D=1.30)$ in Round 3 .

The dialogue on social well-being had a similar flow. In Round 1, Panelist 7 discussed the significance of social well-being through spectator sport by expressing "The sociopsychological aspects to me is the more important theme as it...has the more direct relationship 
with the sport spectator experiences and its impact on other relevant outcomes." As the panel progressed into Round 2, social well-being continued to be deliberated. Panelist 9 conveyed the potential impact of social well-being on long-term physical well-being by stating:

Furthermore, we know that social isolation and loneliness are deleterious to physical health over time. Social relationships are crucial and, understanding how spectator sport can foster meaningful identities for people is key. The evidence is clear: Meaningful social identities have positive effects on social, psychological, well-being, and physical health measures.

The Round 3 survey results confirmed the potential value of leveraging spectator sport to enhance social well-being. With a mean of 6.00, the statement "Enhancing social well-being (e.g., sense of belonging, social integration) is an important and viable opportunity for spectator sport to benefit population health" was the fifth and final statement to receive a mean score of 6.00 or higher. Thus, opportunities to possibly enhance both mental well-being and social wellbeing through spectator sport earned high levels of meaning from the panel.

\section{Relating to Stakeholders}

The panel raised the issue of sport researchers needing to identify with the interests and perspectives of various stakeholders and not operate in an academic silo. In the first two rounds of data collection, panelists' comments indicated that if meaningful benefits are possible through spectator sport, researchers will need to work in collaboration with other stakeholders and address challenges relevant to them. For instance, in Round 1 Panelist 12 affirmed:

Spectator sport could improve its relevance if the cultural meanings surrounding spectator sport involved things other than capitalism. Research and education can't be the drivers of this without industry support. It's an important topic to examine and discuss, 
but until the industry sees the utility it will have little to no impact.

This theme was the most discussed topic in Round 2. As the discourse expanded, Panelist 2 offered the following viewpoint:

Research... needs to take sector differences seriously. Events occur across sectors. In the case of the not-for-profit sector, the health aspect needs to be built into mission (as notfor-profit organizations are required by law to evaluate strategy with reference to serviceto-mission). In the case of the public (government) sector, the political (especially stakeholder) issues are amplified exponentially. The politics and stakeholder management aspects will need focused examination and elaboration. In the for-profit case, we can quack all we like about the importance of health, but (just like CSR) there has to be a bottom-line relevancy, which needs to be convincingly demonstrated.

Panelist 4 concurred by stating "Unless sports teams embrace wholeheartedly initiatives to get healthy... this is a very large challenge... This will require investment of a serious level and not just lip-service CSR initiatives. There is a necessity to normalize these behaviors." In Round 3, all three statements tied to this theme earned mean ratings of 5.40 or higher. The panel assigned the sixth highest level of agreement $(M=5.60, S D=1.18)$ to the statement "Sport management scholars must identify with the interests and perspectives of various stakeholders (e.g., sport industry leaders, policymakers) to produce meaningful research and leverage spectator sport for population health." The statement "Connecting spectator sport research effectively with practice and policy is critical to advancing the link between population health and the sport management field" was the next highest $(M=5.53, S D=1.55)$. Furthermore, the statement "The sport industry's commitment and support (e.g., providing resources, implementing promotional activities) are critical to advancing population health through spectator sport" was the final 
statement to have a mean score above $5.00(M=5.40, S D=1.12)$.

\section{Distinguishing Health Effects of Spectator Sport}

The panelists noted how essential it will be for researchers to demonstrate distinctive health effects of spectator sport that are difficult to find in other forms of leisure or entertainment. This was an emphasis from the outset of data collection and was among the most referenced topics in Round 1. For example, Panelist 16 offered the following considerations:

There are two fundamental questions: (1) should we continue to be allocating time and resources to an area of research in which current evidence suggests equivocal impacts; (2) what are the fundamental assumptions (or logic models) that lead us to believe sport events can impact upon population health, and are these based on intuition and ideology, or are they genuinely evidence based?

As the discourse proceeded in Round 2, the panel regularly returned to this call to the field. One cognition needed by spectator sport scholars was expressed by Panelist 9:

The issue becomes that the majority of the work exploring how sport spectatorship influences health outcomes is focused on sport, rather than sport in relation to other alternative activities... To be taken seriously in health policy, sport spectatorship - as an activity - needs to demonstrate why or how it offers additive benefits that cannot be realized through other activities (that cost less money in many contexts).

In Round 3, the statement "To advance the role of spectator sport in promoting population health, the distinctive health effects of sport need to be demonstrated" was tied for the seventh highest mean score by the panel $(M=5.53, S D=1.30)$.

\section{Reciprocity between Spectator Sport and Environmental Well-Being}

The final two themes received the highest levels of disagreement among the panel. One 
debated theme was the importance environmental well-being plays in population health benefits derived from spectator sport or the possibilities of spectator sport promoting environmentally healthy behaviors to its consumers. Some panelists viewed this topic as among the most important in the sport management field and noted the reciprocal benefits possible between spectator sport and environmental well-being. Other panelists did not regard this linkage as a critical consideration for future researchers or practitioners. Panelist 12 brought the topic into the panel dialogue in Round 1 by stating:

Spectator sport can set an example by promoting attitudes and behaviors that positively influence population health. From an ecosystem perspective this includes not only people, but also the natural environment in which they live... Population health needs to be expanded to include the entire ecosystem in which sport spectators live. Upon being presented this statement in Round 2, other panelists concurred with the significance of the relationship between environmental well-being and spectator sport. Panelist 2 contended: Environmental stewardship is arguably the most significant policy issue of the 21 st century. The issue might include health aims, but the effects of the environment are deeper and more subtle. It's like the frog that doesn't know the water is heating up, and so boils to death. The environment is too often taken for granted.

Other panel members, however, disagreed or were uncertain with the relevancy of the environment and the sport spectating experience. Panelist 7 asserted "This is a far-fetched relationship to me. There are a lot of factors that need to be understood first before we make a connection with spectatorship and environmental health." Panelist 1 discussed researcher efforts that were still needed:

I believe that it would be useful to do research focused on how some sports or events 
with a stronger link with the natural environment (e.g., golf) can help to promote environmental health. This could be extended to some sport events. However, 'sport' as a driver of environmental health seems to me an idea that still requires more theoretical elaboration in order to gauge the attention and credibility of society at a large.

In Round 3, the statement "Spectator sport has great potential to be part of the solution to addressing environmental well-being in the 21 st Century" was allocated a mean score of 4.80 and standard deviation of 1.42 , which made it one of the most disputed topics among the panel.

\section{Leveraging Spectator Sport for Participant Sport}

The relationship between sport spectating and participation, or sport consumers being motivated to participate in sport through their spectating, was deemed least critical among the panel and signified where the most robust paradigmatic debate occurred. In Round 1, panelists often argued that the link between watching sport versus playing sport was largely tenuous. Panelist 5 maintained:

People are incredibly busy, and we need a better understanding to what extent spectator sport and sport participation are competing for leisure time. Does watching lead to playing? There is anecdotal evidence that this might occur, but there is a lot of research that suggests that this does not occur.

As the discourse progressed in Round 2, the panel addressed what would be needed to leverage sport spectating to have any impact on participation. Panelist 2 and Panelist 7 commented:

There needs to be work identifying points of cross-leverage, and then testing crossleveraging tactics. Of course, those who are responsible for butts-in-seats for spectator events are not typically interested in participation, while those responsible for participation do not see it as their challenge to promote spectating. 
The challenges are to find the proper partners to deliver health related programs in tandem with the spectator experience. However, the spectators have to be motivated to participate in such activity above and beyond what they are doing already. If we are talking about participatory sport, then sport managers have to find ways to engage the non-participants. Challenges with that is getting them from amotivation to motivation stages. Ideal examples do not exist.

Other panelists agreed that partnerships with relevant stakeholders and not operating in a sport silo were essential to deriving any sport participation benefits, if possible, through spectating. As data collection concluded in Round 3, the statement "Leveraging spectator sport for sport participation is critical to advancing the role of the sport management field in addressing population health issues" received the lowest mean score $(M=4.60)$ and highest standard deviation $(S D=1.92)$ among the 11 emergent themes identified by the expert panel.

\section{Discussion}

This study aimed to understand the present state of, and future needs for, spectator sport and population health research based on identified governing paradigms in sport management. To achieve this, the first research question (RQ1) asked what is the present state of spectator sport and population health research. The results reveal clear points of agreement among the panel for where the field is presently: that sport management research has tended to oversell or oversimplify spectator sport as having a positive and direct relationship with well-being outcomes.

In providing this assessment, the most consistent epistemological position (cf. Collis \& Hussey, 2014; Frisby, 2005) taken by the panelists, indicated in the data, was that spectator 
sport's influence on population health should be viewed as inherently neutral. Ontologically, the expert panel recognized that context is crucial to understand the relationship between spectator sport and population health. Key contextual considerations include the temporal health effects beyond the sport spectating experience and other variables in individuals' lives (e.g., health behaviors, major life events, participation in other activities) that can influence population health besides spectator sport. In this regard, the panel indicated that there is a lack of evidence regarding the distinctive population health effect of spectator sport relative to other pursuits and this state of knowledge is attributable to the tendency of past researchers to overlook factors beyond sport. The experts' methodological position, like Frisby (2005), did not favor quantitative, qualitative, or mixed-method approaches, but viewed sport management's research on the topic as constrained due to limited data collection contexts, theoretical frameworks, or efforts to collaborate outside the discipline.

The second research question (RQ2) examined what future needs exist to advance spectator sport and population health research. From a methodological perspective, the future needs highlighted by the panel included longitudinal research in more varied contexts, more diverse theorization in the field, and more interdisciplinary collaboration suitable for addressing complex topics like spectator sport and population health. In addition, our results substantiate that mental and social well-being represent two domains of health with more opportunities for sport management researchers to contribute. This future research direction aligns with a growing emphasis in the literature on examining spectator sport's links with mental and social well-being both within and beyond the discipline (e.g., Inoue, Funk, et al., 2015; Kim \& James, 2019; Pawlowski et al., 2014; Schlegel et al., 2017; Wann et al., 2017). To advance these domains through spectator sport, the expert panel offered two recommendations for sport management 
researchers. First, the panel members advocated for researchers to move out of their sport management silo and conduct empirical studies of spectator sport that are relevant to other stakeholders (e.g., policymakers, spectator-centered sport organizations). Relevancy of research was viewed through the lens of scholars not just informing other stakeholders of a study's findings, but also in allowing input, addressing pertinent topics, and demonstrating how results can be beneficially applied. Second, the panelists encouraged researchers to move beyond determinations of whether spectator sport has a positive or negative effect on well-being and begin to distinguish effects of spectatorship from what can be found with other forms of leisure or entertainment. This was deemed necessary if spectator sport is to be more widely viewed in public policy discourse as a legitimate tool for population health.

While the future needs identified above received unambiguous support from the panel, clear divergences emerged amongst the panelists on how spectator sport and environmental wellbeing can affect each other. In line with a growing interest in this topic (McCullough et al., 2020), some panelists regarded the subject as one of the most critical for sport management research currently and in the future. However, other panelists did not prioritize it and viewed other issues as more vital to research and influence population health. Though sport management researchers have studied environmental sustainability (Casper et al., 2012), our Delphi study indicates that the reciprocal relationship between spectator sport and environmental well-being needs future empirical assessment and represents one avenue of meaningful collaboration with spectator-centered sport organizations, which is a favored research topic by practitioners (Inoue et al., 2019). The least optimism was expressed on the issue of sport spectatorship influencing sport participation and its effect on physical well-being. Based on a body of sport management research (Weed et al., 2015), panelists were most skeptical about sport spectating influencing 
non-participants to become regular sport participants. Establishing feasible examples or models of how spectator sport can be leveraged for participant sport are needed in the field, if any are possible through empirical study.

For other population health topics in which the panel showed more optimism and agreement on importance, there was still a wide range of viewpoints expressed by the panel. The varying perspectives can partly be explained by the panelists' different backgrounds and research foci that produced divergences. Such diversity was intentionally sought to fully explore the link between spectator sport and population health. However, if additional sport management scholars had been added to the panel, the emerging forecast would have likely had more variances and final analysis would have been even more complex. It is crucial to mention that producing consensus is not the sole aim of the Delphi technique. This method is also used to generate forecasts and compel participating experts to reexamine concepts and underlying assumptions (Linstone \& Turoff, 2011). Thus, while there were places of agreement, the present study achieved its primary purpose of understanding the present state of, and future needs for, spectator sport and population health research based on prevailing paradigms in sport management.

The "constellation of concepts, values, perceptions, and practices shared by a community," as Capra (1996, p. 6) described, was evident in the data and the current paradigmatic outlook for spectator and population health research. Paradigmatic debate among the panel and in the broader sport management field is not problematic or a new phenomenon, but necessary for its continued health and legitimacy (Amis \& Silk, 2005; Bowers et al., 2014). This ongoing “malaise”, as Chalip (2006, p. 1) described, is needed for sport management's maturation, assertion of its significance as an academic endeavor, and relevance to practitioners. 
Given that this discourse has continued over many years and been a central appeal of numerous Zeigler Award recipients in NASSM (e.g., Chalip, 2006; Doherty, 2012; Frisby, 2005), it is feasible that paradigmatic debate is a decades-long process essential for any field to undergo. Like other disciplines, sport management is still evolving, and the emergence of research paradigms requires the refinement of assumptions, possibilities, goals, directions, relevant stakeholders, needs, values, and ways of thinking (Costa, 2005). The field may be in the early stages of this process when discussing future directions and realistic applications of spectator sport and population health, as a broad research area within sport management. Furthermore, while spectator sport and population health were the focus, several of the themes and panelists' comments (e.g., overselling or oversimplifying sport, improving interdisciplinary collaboration and research design, relating to stakeholders) may inform sport management research in general, regardless of topic.

The results of this study partly confirm the themes and framework offered by Inoue, Berg, et al.'s (2015) scoping study, which were derived from a body of spectator sport literature that was developed predominately in other fields beside sport management. For instance, spectator sport's role in mental and social well-being, two types of well-being signifying health and featured in their framework, were recognized by our panel as worthy and viable avenues for spectator sport to benefit population health. Moving beyond this prior understanding, the findings from the current Delphi study provide new insights into the spectator and population health research in sport management by highlighting areas of research where further refinement is needed. Notably, the prospects of positively influencing sport participation, which can heavily affect physical well-being, through spectator sport (Weed et al., 2015) was viewed with the greatest degree of skepticism by the panel. If there are possibilities to leverage spectator sport for 
participant sport, event, sport, and non-sport stakeholders must work conjointly with each other to identify resources and opportunities to capitalize upon spectator sport to build sport participation (Chalip et al., 2017). The need for collaborative partnerships with spectator sportcentered organizations was repeatedly stressed by the panel. It is also critical to note that leveraging is not a task that can be effectively completed by a single entity (Chalip et al., 2017; Edwards \& Rowe, 2019). Additionally, panelists frequently raised concerns beyond promoting a more physically active population. In all three rounds of data collection, panel members highlighted other health-related behaviors that have a direct relationship with physical wellbeing, such as frequent tobacco use, heavy alcohol consumption, and poor nutritional intake. The current results reveal the relevance of these health-related behaviors and themes, yet demonstrate that leading sport management experts were not optimistic about scholars or practitioners' ability or willingness to foster more healthy behaviors in a spectator sport context. Further, throughout data collection panelists did not place a high level of importance on themes related to spectator sport's influence on mortality, crime and suicide, or role modeling effects of athletes. This indicates that these themes, which were originally advanced by Inoue, Berg, et al., have been given more prominence in other fields of study.

This Delphi study allows for comparison and identification of collaborative opportunities, or bridging research and practice as commonly described, between leading sport management experts and practitioners in Inoue et al.'s (2019) consultation. As the results demonstrate, the panel recognized the necessity to produce empirical research that is relevant to spectatorcentered sport organizations. The panelists' prioritization of mental and social well-being aligns with practitioners' preference for these two forms of well-being as a research focus more likely to receive recognition from such organizations. Inoue et al. (2019) also noted an increasing 
number of studies recently published in sport management journals on mental well-being through spectator sport, but a paucity of studies examining social well-being. Our expert panel repeatedly urged collaborative research between scholars from more than one discipline along with spectator-centered sport practitioners. Such multi-party partnerships highlight a need for industry partners to be involved from the outset when research agendas are developed, which may allow opportunities for distinct data to be collected, more spectator sport research questions to be answered, and enduring challenges experienced by practitioners to be addressed. Otherwise, sport management risks developing a research agenda only for itself. Future Delphi studies forecasting the direction of sport management research should consider including both scholars and practitioners on the expert panel.

Finally, the panelists recurrently discussed the harmful effects spectator sport can have on population health, in addition to the positive possibilities, and the need to minimize negative outcomes. This perspective augments existing empirical evidence pointing to the detrimental consequences of sport spectatorship (Kelly et al., 2014; Wakefield \& Wann, 2006; WilbertLampen et al., 2008). Despite this evidence, practitioners are inclined to view the direction of the influence of spectator sport and population health as mostly positive (Inoue et al., 2019). Therefore, it will be crucial for sport management scholars to not only collaboratively engage with spectator-centered sport organizations and demonstrate how their practices can have a constructive effect on population health, but also showcase negative impacts and how those are relevant to such organizations meeting or not meeting their missions and goals. Such sport management research is lacking in theorization and empirical examination (Inoue et al., 2020).

\section{Limitations, Directions for Future Research, and Conclusions}

Despite the expansion of spectator sport and population health research in recent years, 
extensive and diverse empirical studies, done collaboratively and with application to spectatorcentered sport organizations, are needed. Inoue, Berg, et al. (2015) observed that most research done on spectator sport and population health, regardless of field, has been conducted by scholars in North America, Europe, and Australia. While diversity among the expert panel (e.g., research foci, gender) was achieved, a limitation of this study is that all 15 panelists who participated in Round 3 were based in the United States, the United Kingdom, or Canada. The adapted inclusion criteria for this study ensured that all participants had strong expertise on the research topics, but this resulted in an unintended consequence of limited international representation because the invited experts were clustered in a small number of countries. As an academic discipline, sport management's continued development has included the establishment of more continental associations (e.g., the Asian Association for Sport Management, the Asociacion Latinoamericana de Gerencia Deportiva, the African Sport Management Association) that represent added contexts in which spectator sport may be experienced and researched differently. Research from additional continental contexts would be beneficial for sport management and may allow the field to have a more substantial voice in the broader interdisciplinary health discourse on spectator sport and population health.

The first two rounds of data collection for this study occurred before the global outbreak of the coronavirus disease (COVID-19). Data collection in Round 3, however, concluded after the pandemic progressed to most countries worldwide. Therefore, in two of three data collection rounds the expert panelists offered their feedback prior to a distinct period in world history. Had all three rounds of data collection occurred during the pandemic, the panel's discourse may have included considerations for how spectator-centered sport organizations could have helped prevent the spread of COVID-19 or the ethical responsibility these organizations owed to major 
stakeholder groups, such as the athletes, consumers, and residents. The lasting effects of COVID-19 on spectator sport and population health offers a compelling avenue for future empirical study (Inoue et al., 2020). For instance, as sport venues open again and social gatherings resume, sport management scholars can demonstrate how sport spectatorship has contributed to social and mental well-being following an extended period of widespread social distancing and increased anxiety in many parts of the world.

The expert panel agreed that sport management scholars need to avoid overselling what spectator sport can do for population health and demonstrate distinctive well-being benefits that are difficult to find in other forms of leisure or entertainment. These recommendations offer numerous opportunities to future researchers. First, it would be important to consider moving beyond measuring simply for effects of spectator sport on varying aspects of well-being and instead assess and compare the well-being effects from multiple forms of leisure and entertainment. For example, what, if any, distinctive health benefits are derived from being a season-ticket holder for a local sport team versus attending live music or theatre performances or visiting a theme park? Answering questions like this may require the utilization of new theories and drawing on the expertise of scholars in other disciplines, both of which were advocated by the panelists, to explain how spectator sport and the different domains of well-being are related and not just if they are. Second, moving outside the sport management silo and distinguishing spectator sport would allow scholars to accurately inform policymakers on what sport can contribute to the public health agenda, which the panel viewed as an abiding necessity for the field. Further, longitudinal research can offer critical assessment of spectator sport and population health. Beyond identifying distinct well-being effects of spectator sport with one-time or short-term pre/post measurements, researchers should spread out data collection (e.g., next 
week, next month, next year) to determine the longevity of health effects on spectators' lives. This would allow sport management scholars to begin moving beyond collecting chance measurements or observations. Finally, researchers are urged to occasionally query, perhaps with the Delphi technique, the paradigms that govern research agendas in the field as the body of research and best practices advance. The coexistence of emergent paradigms with established paradigms is to the benefit of sport management (Amis \& Silk, 2005). This Delphi study identified the predominant paradigms for spectator sport and population health research in the current sociotemporal context.

In conclusion, spectator sport and population health research is an expansive topic that is relevant to many scholars in sport management studying numerous issues directly linked to at least one aspect of well-being. This was reflected in the diverse research foci of the expert panel. This study did not aim to identify one dominant paradigm regarding spectator sport and population health. Rather it sought to explain some of the current leading paradigms that will shape the assumptions, values, questions, methods, and impact sport management researchers will have on this broad topic. With multiple domains of personal well-being affected by spectator sport, improving population health is an enduring, interdisciplinary challenge for which sport management can have significant input. It is hoped that necessary paradigmatic debate, as facilitated in this study, will influence distinct empirical study and innovative spectator-centered sport organizations' practice to benefit population health. 


\section{References}

Amis, J., \& Silk, M. (2005). Rupture: Promoting critical and innovative approaches to the study of sport management. Journal of Sport Management, 19(4), 355-366.

Anderson, A., Dixon, M. A., Oshiro, K. F., Wicker, P., Cunningham, G. B., \& Heere, B. (2019). Managerial perceptions of factors affecting the design and delivery of sport for health programs for refugee populations. Sport Management Review, 22(1), 80-95.

Berg, B. K., Fuller, R. D., \& Hutchinson, M. (2018). "But a champion comes out much, much later": A sport development case study of the 1968 U.S. Olympic team. Sport Management Review, 21(4), 430-442.

Berg, B. K., Warner, S., \& Das, B. M. (2015). What about sport? A public health perspective on leisure-time physical activity. Sport Management Review, 18(1), 20-31.

Bowers, M. T., Green, B. C., \& Seifried, C. S. (2014). "Let the marketplace be the judge": The founders reflect on the origins and trajectory of NASSM. Journal of Sport Management, $28(5), 565-587$

Capra, F. (1996). The web of life: A new scientific understanding of living systems. Anchor.

Casper, J., Pfahl, M., \& McSherry, M. (2012). Athletics department awareness and action regarding the environment: A study of NCAA athletics department sustainability practices. Journal of Sport Management, 26(1), 11-29.

Chalip, L. (2006). Toward a distinctive sport management discipline. Journal of Sport Management, 20(1), 1-21.

Chalip, L., Green, B. C., Taks, M., \& Misener, L. (2017). Creating sport participation from sport events: Making it happen. International Journal of Sport Policy and Politics, 9(2), 257276. 
Chalip, L., Schwab, K., \& Dustin, D. (2010). Bridging the sport and recreation divide. Schole: $A$ Journal of Leisure Studies and Recreation Education, 25(1), 1-10.

Chelladurai, P. (1992). Sport management: Opportunities and obstacles. Journal of Sport Management, 6(3), 215-219.

Chelladurai, P. (2014). Managing organizations for sport and physical activity (4th ed.). Holcomb Hathaway.

Collins, D. R., \& Heere, B. (2018). Sunday afternoon social capital: An ethnographic study of the Southern City Jets Club. European Sport Management Quarterly, 18(4), 439-458.

Collis, J., \& Hussey, R. (2014). Business research: A practical guide for undergraduate and postgraduate students (4th ed.). Macmillan International Higher Education.

Costa, C. A. (2005). The status and future of sport management: A Delphi study. Journal of Sport Management, 19(2), 117-142.

Dalkey, N., Brown, B., \& Cochran, S. (1970). Use of self-ratings to improve group estimates: Experimental evaluation of Delphi procedures. Technological Forecasting, 1(3), 283291.

Dalkey, N., \& Helmer, O. (1963). An experimental application of the Delphi method to the use of experts. Management Science, 9(3), 458-467.

Doherty, A. (2012). “It takes a village:” Interdisciplinary research for sport management. Journal of Sport Management, 27(1), 1-10.

Edwards, M. B., \& Rowe, K. (2019). Managing sport for health: An introduction to the special issue. Sport Management Review, 22(1), 1-4.

Frisby, W. (2005). The good, the bad, and the ugly: Critical sport management research. Journal of Sport Management, 19(1), 1-12. 
Goulding, C. (2002). Grounded theory: A practical guide for management, business, and market researchers. Sage.

Hsu, C.-C., \& Sandford, B. A. (2007). The Delphi technique: Making sense of consensus. Practical Assessment, Research, and Evaluation., 12(1), 1-8.

Inoue, Y., Berg, B. K., \& Chelladurai, P. (2015). Spectator sport and population health: A scoping study. Journal of Sport Management, 29(6), 705-725.

Inoue, Y., Berg, B. K., \& Chelladurai, P. (2019). Spectator sport and population health: A consultation with U.S. college athletics employees. Journal of Global Sport Management. https://doi.org/10.1080/24704067.2019.1566755

Inoue, Y., Funk, D. C., Wann, D. L., Yoshida, M., \& Nakazawa, M. (2015). Team identification and postdisaster social well-being: The mediating role of social support. Group Dynamics: Theory, Research, and Practice, 19(1), 31-44.

Inoue, Y., Sato, M., \& Filo, K. (2020). Transformative sport service research: Linking sport services with well-being. Journal of Sport Management, 34(4), 285-290.

Inoue, Y., Sato, M., Filo, K., Du, J., \& Funk, D. C. (2017). Sport spectatorship and life satisfaction: A multicountry investigation. Journal of Sport Management, 31(4), 419-432.

Inoue, Y., Sato, M., \& Nakazawa, M. (2018). Association between sporting event attendance and self-rated health: An analysis of multiyear cross-sectional national data in Japan. Global Health Research and Policy, 3(1). https://doi.org/10.1186/s41256-018-0068-9

Irwin, R. L., \& Ryan, T. D. (2013). Get real: Using engagement with practice to advance theory transfer and production. Sport Management Review, 16(1), 12-16.

Jacobs, N. C., Dehue, F., Völlink, T., \& Lechner, L. (2014). Determinants of adolescents' ineffective and improved coping with cyberbullying: A Delphi study. Journal of 
Adolescence, 37(4), 373-385.

Kelly, S. J., Ireland, M., Alpert, F., \& Mangan, J. (2014). The impact of alcohol sponsorship in sport upon university sportspeople. Journal of Sport Management, 28(4), 418-432.

Kim, J., \& James, J. D. (2019). Sport and happiness: Understanding the relations among sport consumption activities, long- and short-term subjective well-being, and psychological need fulfillment. Journal of Sport Management, 33(2), 119-132.

Kindig, D. (2007). Understanding population health terminology. The Milbank Quarterly, 85(1), $139-161$.

Kuhn, T. S. (1996). The structure of scientific revolutions (3rd ed.). University of Chicago Press.

Lera-López, F., Ollo-López, A., \& Sánchez-Santos, J. M. (2020). Is passive sport engagement positively associated with happiness? Applied Psychology: Health and Well-Being, Advance online publication. https://doi.org/10.1111/aphw.12227

Linstone, H. A., \& Turoff, M. (2011). Delphi: A brief look backward and forward. Technological Forecasting and Social Change, 78(9), 1712-1719.

Mahony, D. F. (2008). No one can whistle a symphony: Working together for sport management's future. Journal of Sport Management, 22(1), 1-10.

Mallen, C., Adams, L., Stevens, J., \& Thompson, L. (2010). Environmental sustainability in sport facility management: A Delphi study. European Sport Management Quarterly, $10(3), 367-389$.

McCullough, B. P., Orr, M., \& Kellison, T. (2020). Sport ecology: Conceptualizing an emerging subdiscipline within sport management. Journal of Sport Management, 34(6), 509-520.

Musa, H. D., Yacob, M. R., Abdullah, A. M., \& Ishak, M. Y. (2015). Delphi method of developing environmental well-being indicators for the evaluation of urban sustainability 
in Malaysia. Procedia Environmental Sciences, 30, 244-249.

Patten, M. L. (2014). Understanding research methods: An overview of the essentials $\left(9^{\text {th }}\right.$ ed.). Pyrczak.

Pawlowski, T., Downward, P., \& Rasciute, S. (2014). Does national pride from international sporting success contribute to well-being? An international investigation. Sport Management Review, 17(2), 121-132.

Pfleegor, A., Katz, M., \& Bowers, M. T. (2017). Publish, perish, or salami slice? Authorship ethics in an emerging field. Journal of Business Ethics, 156(1), 189-208.

Rowe, K., Shilbury, D., Ferkins, L., \& Hinckson, E. (2013). Sport development and physical activity promotion: An integrated model to enhance collaboration and understanding. Sport Management Review, 16(3), 364-377.

Rowe, G., \& Wright, G. (1999). The Delphi technique as a forecasting tool: Issues and analysis. International Journal of Forecasting, 15(4), 353-375.

Ryan, R. M., \& Deci, E. L. (2001). On happiness and human potentials: A review of research on hedonic and eudaimonic well-being. Annual Review of Psychology, 52(1), 141-166.

Schlegel, A., Pfitzner, R., \& Koenigstorfer, J. (2017). The impact of atmosphere in the city on subjective well-being of Rio de Janeiro residents during (vs. Before) the 2014 FIFA World Cup. Journal of Sport Management, 31(6), 605-619.

Skulmoski, G.J., Hartman, F.T., \& Krahn, J. (2007). The Delphi method for graduate research. Journal of Information Technology Education, 6, 1-21.

Soria, K. M., \& Stebleton, M. J. (2013). Social capital, academic engagement, and sense of belonging among working-class college students. College Student Affairs Journal, 31(2), $139-153$. 
Taks, M., Littlejohn, M., Snelgrove, R., \& Wood, L. (2016). Sport events and residential happiness: The case of two non-mega sport events. Journal of Global Sport Management, $1(3-4), 90-109$.

Wakefield, K. L., \& Wann, D. L. (2006). An examination of dysfunctional sport fans: Method of classification and relationships with problem behaviors. Journal of Leisure Research, $38(2), 168-186$

Wann, D. L., Hackathorn, J., \& Sherman, M. R. (2017). Testing the team identification-social psychological health model: Mediational relationships among team identification, sport fandom, sense of belonging, and meaning in life. Group Dynamics: Theory, Research, and Practice, 21(2), 94-107.

Weber, R. P. (1990). Basic content analysis (2 ${ }^{\text {nd }}$ ed.). Sage.

Weed, M., Coren, E., Fiore, J., Wellard, I., Chatziefstathiou, D., Mansfield, L., \& Dowse, S. (2015). The Olympic Games and raising sport participation: A systematic review of evidence and an interrogation of policy for a demonstration effect. European Sport Management Quarterly, 15(2), 195-226.

Weese, W. J. (1995). If we're not serving practitioners, then we're not serving sport management. Journal of Sport Management, 9(3), 237-243.

Wilbert-Lampen, U., Leistner, D., Greven, S., Pohl, T., Sper, S., Völker, C., ... others. (2008). Cardiovascular events during World Cup soccer. New England Journal of Medicine, $358(5), 475-483$.

World Health Organization. (n.d.). Constitution. Retrieved August 3, 2020, from https://www.who.int/about/who-we-are/constitution 


\section{Appendix A: Rounds 1 and 2 Panel Questions}

In this first data collection round, panel members were presented with the below questions to begin the Delphi study along with brief background information, definition of key terms, and the nine research themes identified by Inoue, Berg, et al. (2015). In the second data collection round, the panel was presented with the below questions along with a brief narrative for context and example panelists' statements offered in the first round.

\section{Round 1 Questions}

Q1. What relevance does spectator sport's influence on population health have for sport management research and education?

Q2. What importance do you assign to the research themes regarding the influence of spectator sport on population health for the current sport management field? Please explain which themes you view as more important and less important. Why?

Q3. For the existing themes, what are specific research topics that future research should seek to address to advance the field's understanding of spectator sport's influence on population health?

Q4. What other areas of research are critical to advance the field's understanding of the influence of spectator sport on population health?

Q5. Looking toward the future, what is the ideal status for spectator sport and population health in the sport management field and what is necessary to realize that status?

\section{Round 2 Questions}

Q1. What are the challenges that the field of sport management faces when considering how sport can be leveraged in population health efforts? What are ideal conditions or examples of how spectator sport could be effectively leveraged or strategically used to benefit population health? Are there fundamental issues preventing sport management scholars from meaningfully engaging with health and health policy?

Q2. What role should the sport industry play in bridging research and practice as it relates to advancing population health through spectator sport?

Q3. What is needed from the sport management field to establish the relationship between spectator sport and participant sport? How can findings from academic research be more effectively communicated to inform policymakers and industry practitioners?

Q4. What issues need to be addressed in sport management research to more clearly determine how spectator sport can be utilized to benefit mental and social health among the population?

Q5. What are the assumptions, processes, or mechanisms researchers should consider when examining spectator sport as a tool to help achieve health goals or behavior change among the population?

Q6. What importance, if any, do you assign to the role environmental health (i.e., protection of the natural environment) can have in affecting population health outcomes from sport spectating? What is needed to advance understanding of the relationship between the natural environment and sport spectating and its influence on population health aims? 


\section{Appendix B: Statements of Consent and Descriptive Statistics (Round 3)}

In this final data collection round, panel members were presented with the statements of consensus that emerged from the first two rounds. For each of the statements, panelists indicated their level of agreement using the following seven-point Likert scale: $1=$ strongly disagree, $2=$ disagree, $3=$ somewhat disagree, $4=$ neither agree or disagree, $5=$ somewhat agree, $6=$ agree, 7 strongly agree. Panelists were also provided space beneath each item within which to supplement their rating with final comments or clarifications.

\begin{tabular}{|c|c|c|c|}
\hline Statement & $N$ & Mean & $S D$ \\
\hline $\begin{array}{l}\text { Sport management researchers must avoid overselling or } \\
\text { oversimplifying the role spectator sport can have to benefit } \\
\text { population health. }\end{array}$ & 15 & 6.67 & 0.49 \\
\hline $\begin{array}{l}\text { Collaboration with other disciplines beyond sport } \\
\text { management will be important in advancing the topic of } \\
\text { spectator sport and population health. }\end{array}$ & 15 & 6.53 & 0.83 \\
\hline $\begin{array}{l}\text { Enhancing mental well-being (e.g., life satisfaction, } \\
\text { happiness) is an important and viable opportunity for } \\
\text { spectator sport to benefit population health. }\end{array}$ & 15 & 6.13 & 1.30 \\
\hline $\begin{array}{l}\text { Improvements in research designs and theorization are } \\
\text { crucial to offer robust evidence regarding the relationships } \\
\text { between spectator sport and population health. }\end{array}$ & 15 & 6.07 & 0.59 \\
\hline $\begin{array}{l}\text { Enhancing social well-being (e.g., sense of belonging, social } \\
\text { integration) is an important and viable opportunity for } \\
\text { spectator sport to benefit population health. }\end{array}$ & 15 & 6.00 & 1.00 \\
\hline $\begin{array}{l}\text { Sport management scholars must identify with the interests } \\
\text { and perspectives of various stakeholders (e.g., sport industry } \\
\text { leaders, policymakers) to produce meaningful research and } \\
\text { leverage spectator sport for population health. }\end{array}$ & 15 & 5.60 & 1.18 \\
\hline $\begin{array}{l}\text { Connecting spectator sport research effectively with practice } \\
\text { and policy is critical to advancing the link between } \\
\text { population health and the sport management field. }\end{array}$ & 15 & 5.53 & 1.55 \\
\hline $\begin{array}{l}\text { To advance the role of spectator sport in promoting } \\
\text { population health, the distinctive health effects of sport need } \\
\text { to be demonstrated. }\end{array}$ & 15 & 5.53 & 1.30 \\
\hline $\begin{array}{l}\text { The sport industry's commitment and support (e.g., providing } \\
\text { resources, implementing promotional activities) are critical to } \\
\text { advancing population health through spectator sport. }\end{array}$ & 15 & 5.40 & 1.12 \\
\hline $\begin{array}{l}\text { Spectator sport has great potential to be part of the solution to } \\
\text { addressing environmental well-being in the } 21 \text { st Century. }\end{array}$ & 15 & 4.80 & 1.42 \\
\hline $\begin{array}{l}\text { Leveraging spectator sport for sport participation is critical to } \\
\text { advancing the role of the sport management field in } \\
\text { addressing population health issues. }\end{array}$ & 15 & 4.60 & 1.92 \\
\hline
\end{tabular}

